\title{
Poesía gallega desde 1975 hasta hoy: entre la palabra y la realidad
}

\author{
Helena GonZÁLEZ Fernández
}

Universidad de Barcelona

\section{"DIGO PALABRA CON PLOMO Y CON ARRASTRES"' (XOSÉ LUIS MÉNDEZ FERRÍN)}

El panorama poético gallego de la transición y de la década de los ochenta se puede explicar según las diferentes soluciones propuestas a un conflicto permanente: la tensión entre ideología y estética. En aquel momento el problema ni era nuevo ni era un ejemplo aislado en un contexto histórico dominado por los cambios políticos pero, en esta vuelta a la espiral, el diálogo entre la literatura y la sociedad gallegas se encuentra por vez primera con la posibilidad histórica de legitimar muchas de las reivindicaciones nacionales.

Escribir en gallego era (sigue siendo) una opción marcada. Y aún más. Los escritores se sentían obligados a intervenir en el decurso social y en la forja de la nueva identidad nacional. Casi ningún poeta es ajeno a esta cuestión, e incluso los más esteticistas se ven empujados a tomar postura en muchas ocasiones ante esta polémica reconstrucción. En este sentido, lo que en la literatura española se nos pinta como un simple cambio de rumbo estético, porque durante el postfranquismo el rearme ideológico se concentra en la acción política (GarcíaPosada, 1996: 9), se vive de otra manera en Galicia y en las otras nacionalidades históricas. En 1984, en el I Encuentro de Escritores de Galicia, Euskalerria y Paiisos Catalans, se recoge este conflicto, que les es común, entre el compromiso con la articulación de las nacionalidades (esto es, la proyección social de la escritura) y la búsqueda de un espacio de normalidad para el escritor ${ }^{2}$.

\footnotetext{
1 Todas las traducciones son mías.

2 Así, por una parte se incide en que "a normalización -relación plena entre feito literario e sociedade-- das literaturas e das linguas das nosas nacións só será posíbel se cada unha destas nacións se constitúe en estado integramente soberano" y al mismo tiempo se desvincula esta reivindicación política de la práctica literaria: "Constatamos o cambio producido, nalgunhas literaturas máis que noutras, nas motivacións ou impulsos que levan á escrita. As razóns patrióticas non son xa
} 
Este conflicto estético básico se fue formulando de maneras diferentes entre dos extremos: por un lado, forjar una poesía verdaderamente revolucionaria (revolucionaria en sus objetivos y en su forma) y aprovechar al máximo la oportunidad histórica de transformar la sociedad y forjar una nueva poética nacional $^{3} ; y$, por otra optar por un camino de normalización integral acelerada que nos equiparase a las sociedades más asentadas de nuestro entorno. Es necesario tener siempre presente esta tensión para entender en su totalidad la significación de propuestas diversas y encontradas, que surgen a lo largo de estos quince años de poesía. Las antologías, los premios, la proyección exterior, la diversidad genérica ${ }^{4}$, la creación de espacios literarios y para-literarios (revistas, suplementos en diarios, presencia en la televisión, en la música...) y la. (auto)marginación de los círculos poéticos dominantes dificilmente se pueden leer de una manera ingenua en estos años.

La segunda mitad de los años setenta aún es un hervidero de "perpetradores de poesía" que confunden la legitimidad de la reivindicación política con ejercer de revulsivos o guías nacionales a través de la labor literaria. Ellos son los verdaderos epígonos de la poesía civil que había liderado Celso Emilio en el período anterior. Sin embargo 1976 marca simbólicamente una nueva etapa poética que recoge en buena medida la mejor tradición del vanguardismo comprometido (y no sólo de las vanguardias históricas) auspiciado por la izquierda galleguista. Aparece el grupo Rompente, con sus recitales y sus hojas volanderas (Follas de Resistencia Poética) y se publican Con pólvora y magnolias de Méndez Ferrín y Seraogna de Alfonso Pexegueiro. Éste era miembro fundador, junto con Antón R. Reixa, de Rompente, pero al cabo de dos años optó por un camino de investigación poética en solitario, del que surgen libros como A illa das mulleres loucas (1984). El propósito de Rompente era apoderarse de la poesía y "actualizarla" para ayudar a transformar la sociedad, por eso deciden cambiar el canon (prefieren a Manuel Antonio a Celso Emilio) y aproximarse a la realidad rechazando los modelos estilizados que habían heredado. Proponen además cambios importantes en los patrones genéricos, en el soporte e incluso en los canales, y todo esto, además, resultaba extraordinariamente novedoso en el sistema literario gallego. Rompente, en 1976, más que un grupo era una idea de revolución poética de fronteras vagas (no en vano los dos libros antes mencionados de Pexegueiro y Méndez Ferrín se habían publicado bajo ese sello editorial). Estas modificaciones determinan el papel del escritor rompentiano, que se transforma poderosamente en los recitales, háppenings y libros, en los que reniega de la condición tradicional del poeta como bardo,

\footnotetext{
unha das causas fundamentais da escolla, ó terse producido unha canalización destas vocacións car actividades políticas. Aumenta, pois, o número de escritores por motivacións estrictamente literarias ou profesionais" (Documento, 1984).

'Xoán González-Millán, analizando estos cambios en la narrativa, habla de etnopoética, aunque aquí vamos a hablar de poética nacional, para evitar conflictos interpretativos sobre la naturaleza de las reivindicaciones del galleguismo, tal como me sugiere Xesús González Gómez.

${ }^{4}$ Para tener más datos sobre la presencia de los poetas en la narrativa de los 80 , vid. Vilavedra (1996: 233).
} 
guía y sacerdote para dotarlo de una nueva voz, en la que actúa a la vez como sujeto y objeto. No se trata de una poesía testimonial sino de forzar al poeta a acercarse a las contradicciones de su realidad (se trata de un diálogo interdiscursivo con lo contemporáneo), sin miedo a transgredir todas las fronteras genéricas, a juguetear con lo kitch y apostando por "unha poesía cómica, non para facer rir senón para crear unha situación de risa tola que enlace co punto climático do tráxico" (Reixa, 1984).

Rompente fue nuestra vanguardia necesaria y en este sentido son herederos de las ideas y las acciones del dadaismo, del futurismo y del arte pop. En 1977, el grupo se consolida, sale el Silabario da Turbina y los libros de los tres miembros principales del grupo (Antón Reixa, Manuel Romón e Alberto Avendaño). Ellos no eran los únicos que apostaban por el experimentalismo en aquellos momentos pero, sin duda, fueron los que lograron resultados más interesantes e interdisciplinares. En 1982 se publica, postumamente, el último libro del colectivo, A dama que fala, y sus tres integrantes optan por caminos individuales. Reixa es, de los tres, el que más empeño ha puesto en mantener el espíritu de la poética rompentiana, abriendo nuevos campos para su ambicioso proyecto de transformación cultural (música, vídeocreación, teatro, televisión...), y que cuajan en Historia do rock and roll (1985) y en Ringo Rango (1992). Su concepción de la escritura posmoderna y su incidencia en la conformación de una nueva identidad ha sido estudiada en varias ocasiones a la par del Suso de Toro de Tic Tac 5 .

\section{"NO RESPLANDOR DAS HORAS, SON O ESCRIBA SENTADO" (PILAR PALLARÉS)}

A finales de los años setenta surguen otras propuestas colectivas que pretendían enterrar la poesía socialrealista epigonal. Ninguna tuvo la fuerza del colectivo vigués pero en dos de ellas (Cravo Fondo y Loia) encontramos los primeros textos de poetas que triunfarían en la década siguiente: Ramiro Fonte, los hermanos Valcárcel o Manuel Rivas. A partir de 1980, cuando la alternativa más esteticista/intimista empieza a asomar a través de los poemarios de algunos jóvenes poetas (Xavier Baixeras, Pilar Pallarés, Manuel Forcadela o Xulio Valcárcel), el sistema literario gallego parecía querer disfrutar de escribir en normalidad por primera vez.

\footnotetext{
" "Hoxe resulta xa problemático defender un imaxinario colectivo galego, se por tal se entende a imposición dunha incuestionable uniformidade na proxección da identidade nacional. Suso de Toro e Antón Reixa, entre outros, obrigan a falar dunha crise das macrometáforas lexitimadas polos diferentes idearios nacionalistas e a recoñecer a paulatina emerxencia de novas identidades sociais." (GoNZALEZ-MLLÁN, 1994: 79). Baltrusch, en su análisis de la búsqueda de identidad en la literatura gallega contemporánea afirma que "os textos de Antón Reixa podíanse caracaterizar comu deconstrucción proposicional de valores simbólicos" (1995: 91). Vid. también el más reciente sobre la estética de la retranca en Baltrusch (1997).
} 
Mientras iban publicando, haciendo recitales y ganando premios (el Premio Esquío, el más codiciado, sigue mostrando desde 1980, que es un premio fiel a esa línea esteticista/intimista). Pero el verdadero espacio de reunión de los que iban a constituir la poesía dominante de los ochenta es la siempre citada antología de Luciano Rodríguez, Desde la palabra, doce voces (1985), que despertó vivas polémicas pero decisiva a la hora de definir la nómina del discurso poético dominante. Se apoyaba, por una parte, en las voces reunidas en la antología De amor y desamor, en sus dos entregas de 1984 y 1985 (allí estaban Xulio L. Valcárcel, Manuel Rivas, Pilar Pallarés o Miguel Anxo FernánVello) y por otra en ciertos poetas que habían despuntado con éxito y solidez en certámenes y publicaciones (Xosé María Álvarez Cáccamo, Ramiro Fonte, Manuel Forcadela). Parecía constatarse una bipolaridad geográfica entre Vigo y A Coruña que Henrique Monteagudo utilizó como estrategia diegética en su famoso artículo, "Dez anos de poesía galega", aún hoy de cita imprescindible, sobre aquella joven poesía (Monteagudo, 1985).

En la antología de Luciano Rodríguez se pone en cuestión la tensión básica, antes señalada, entre poesía y comunicación y poesía y conocimiento. Los autores allí recogidos toman postura sobre los libros que simbólicamente marcan el nuevo rumbo. Se sugerían diferentes nombres: Alfonso Pexegueiro, Arcadio López-Casanova o Manuel Vilanova. En lo que todos parecían coincidir era en citar Con pólvora y magnolias como libro de importancia capital no sólo por ser publicado en ese año sino también por su calado (claro que algunos se decantan por la pólvora, esto es, los textos más combativos, y otros por las magnolias). Y es que Méndez Ferrín, que pertenece a una promoción anterior, publica desde 1975 dos poemarios capitales que calan en las sucesivas promociones poéticas: el ya citado Con pólvora y magnolias ${ }^{6}$, que fue leído y releído también por la promoción de los años 90, y más recientemente, Estirpe (1994), concebido como un moderno canto épico-lírico en el que se reescriben la historia, el presente y la literatura con una voluntad transformadora. En sus poemarios Méndez Ferrín propone una vía alternativa que integra el culturalismo en la realidad, de tal manera que siempre hay en sus textos propuestas civiles, como en su visión de Percival. De todas maneras, quizas para paliar las connotacións ideológicas y estéticas de Méndez Ferrín se empezó a reivindicar también a un reconocido escritor nada sospechoso de haber padecido el marxismo, Álvaro Cunqueiro, que en 1980 publicaba su último poemario, Herba de aquí e acolá. Y puestos a buscar referentes internos, se llegó a citar a muchos otros poetas clásicos (incluso clasicistas) como Aquilino Iglesia Alva-

6 "Ó tempo que esa intensa dependencia da tradición que se dá en Con pólvora e magnolias propón estratexicamente a algúns autores, indicando un modelo e unha autoridade, silencia outros, xa que non os cita, negándolle-lo lugar preponderante que ata entón ocupaban polo feito de escribiren en galego ou actuaren baixo o impulso da musa cívica. Isto é determinante: a fins do ano 1976, o da publicación deste noso libro, en Galicia non se trata xa de acatar cegamente a tradición, senón de discutila e peneirala, propoñendo así, denda a práctica creadora, un novo canon. Fronte a outros poetas coetáneos $[\ldots]$, por medio das citas que omite e, polo tanto exclúe, exerce unha revisión creativa da tradición literaria galega" (COCHÓN, 1997: 12). 
riño, Luz Pozo Garza y Luis Pimentel. Así lo matiza Ramiro Fonte, un nombre ciertamente indiscutible dentro de esta poesía: "Algo terei que ver, como moitos dos aquí presentes, con Con pólvora e magnolias, aínda que a miña profunda e máis certa debilidade como lector sexa Herba de aquí e acolá "' (Rodríguez 1985: 162).

Desde a palabra, doce voces quería ser la antología de la normalización, de la puesta al día, de la liberación del lastre ideológico para poder investigar en otras direcciones. La realidad se desplaza como una tentación peligrosa (era como verle las orejas al lobo del compromiso político desde el verso) o, simplemente, deja de interesar. En la nómina "oficial" de la poesía dominante pocas voces se enfrentan abiertamente con la contemporaneidad. Entre ellos hay que citar a Xosé María Álvarez Cáccamo (Vigo, 1950), quien alterna su poesía de la memoria y de los espejos con textos combativos, como Prego de cargos (1991), y a Manuel Rivas, un poeta que fue incluido, creo yo que por error, en aquella primera antología de la poesía esteticista, porque, de hecho, el siempre ha renegado de los que escriben versos para huir de la vida y, por el contrario, propone en toda su obra la ternura y el arraigo como formas de empapar la literatura de los conflictos del entorno y de la actualidad. Desde su primer poemario, Libro do Entroido (1979) hasta su último Costa da Morte Blues (1995), lo cotidiano, las gentes y el paisaje (inequívocamente gallegos) se alían con una visión aventurera y mítica. Sus poemas, elaborados con un lenguaje próximo y engañosamente sencillo, son retazos de ternura que apuntan directamente a la emoción del lector, como sus cuentos.

A mediados de la década de los 80 , encauzadas las causas políticas y sancionada la normativa, la atención se concentra en construir una situación de normalidad para el sistema literario gallego (González-Millán, 1994: 146-160). Una de las consecuencias inmediatas fue la consagración de un grupo de poetas jóvenes, de calidad reconocida en los premios y empeñados por construir un registro poético culto en gallego. De manera inmediata la obra de estos poetas se convertía en ejemplo de clasicismo y de modernidad. Se empezó a hablar de una década de oro en la poesía que inmovilizó el modelo. Esta prematura canonización contrastaba poderosamente con las innovaciones que triunfaban en la narrativa.

En la recuperación del espacio que le pertenece al poeta, éste reconquista su función de revelador de la transcendencia, de ordenador y exégeta de cuestiones universales como la vida, la muerte, el amor, la soledad, el tiempo... En los años ochenta el pasado está muy presente en toda la literatura. Mientras la novela se ocupaba en estos años de reapropiarse de la historia colectiva y darle argumentos al presente para construir una identidad que había sido repetidamente silenciada, la poesía dominante se ocupaba sobre todo de recuperar el pasado propio. La memoria individual se convierte en un instrumento eminen-

\footnotetext{
${ }^{7}$ Más tarde el mismo Ramiro Fonte explica de nuevo la importancia de Cunqueiro debido a su amor por la literatura y al "lirismo que planteaba una problemática humana" (FONTE, 1996: 35).
} 
temente lírico (frente a las proclamas épicas de la narrativa histórica). No se trata de una reformulación del saudosismo pero en cierto sentido se le asemeja por la manera de relacionarse con los objetos y con la memoria. La propuesta de estos autores es forjar en gallego una poesía universal y atemporal que en otras culturas se había impuesto en la década anterior. La proyección externa les preocupa mucho. El europeismo es para ellos una manera de modernizarse, de ponerse al día en igualdad de condiciones con otras culturas. La palabra diálogo la repiten hasta la saciedad algunos de estos poetas para explicar su voluntad intertextual, su vocación metaliteraria, "al fin y al cabo somos usufructuarios de los que otros escribieron antes que nosotros" (Fonte, 1996: 35), y su firme deseo de modernidad. La ideología se llega a sentir como un lastre que impide al poeta alzar su voz, salir del minifundio cultural. Esto produce a menudo un alejamiento de la contemporaneidad, de lo cotidiano y de lo colectivo, por supuesto. El presente se nos aparece casi siempre como un lugar irreal y melancólico, con los pies enterrados irremediablemente en el pasado o en un universo simbólico temporal. El individuo lucha por su propio espacio y el escritor se empeña en salir de la marginalidad de lo folclórico. Culturalismo, universalismo y transcendencia serán los pilares de su propuesta. La metaliteratura va más allá de ser considerada una estrategia para reescribir, comprender o revisitar los "universales" poéticos, y se convierte en un objeto de culto. Esto explica la aparición de decadentes poemarios "venecianos" (el término se copia de la literatura española). Se tiene la certeza de que no hay poesía sin diálogo, tanto con los contemporáneos como con la tradición y esto es interpretado por algunos poetas como la posibilidad de convertir la metaliteratura en una técnica preciosista. No menos importante es el deseo común de forjar un registro culto. Esta es su manera de intervenir en la sociedad desde la literatura, de participar en la construcción de una cultura normalizada en pleno conflicto normativo.

Dentro de los que se presenta en 1985 como la poesía dominante había diversas propuestas e incluso diferentes niveles de calidad, por eso el mismo Luciano Rodríguez, convertido en crítico habitual de esta promoción poética, propone una nómina más ajustada en Seis poetas gallegos de hoy (1995), ayudado por la trayectoria que fueron desarrollando los autores en su madurez. Éste es el mejor retrato de la poesía dominante de los ochenta ${ }^{8}$.

Por una parte hay una apuesta muy clara por la poesía del conocimiento. El sujeto poético se interroga a si mismo dentro del mundo que lo rodea. Se trata de una poesía desnuda construida sobre un poderoso simbolismo, sobre los silencios y sobre la autenticidad de las emociones. Pilar Pallarés es su máximo exponente. Con apenas tres libros en su haber se nos aparece como una voz poderosa que va caminando hacia una mayor interiorización y soledad desde Sétima soidade (1984) hasta Livro das devoracións (1996), donde nos descubre la existencia y la vida cotidiana con una voz desgarrada, auténtica y tan cruel que conmociona.

${ }^{8}$ La nómina es la siguiente: Xavier R. Baixeras, Xosé María Álvarez Cáccamo, Xulio L. Valcárcel, Pilar Pallarés, Ramiro Fonte y Miguel anXo Fernán-Vello. 
Por otra se observa una gran tendencia al decadentismo, que se matiza con la presencia del intimismo, la metáfora del viaje, la soledad o la memoria de la infancia como refugio vital. Xavier Rodríguez Baixeras, autor de Anos de viaxe (1981-1987) y Beira Norte (1997) está empeñado en esta recreación da la memoria, pero pautado por un ritmo vigoroso y por el uso habitual de formas métricas clásicas, especialmente el soneto. Su clasicismo formal, su voz por veces épica, se alterna con la narratividad y verso libre. Su mayor empeño como poeta es llevar el verso a la máxima tensión sin constreñir la expresión. Ramiro Fonte, autor que empezó trabajando también con gran empeño el metro y el ritmo en As cidades da nada (1983), articula una buena parte de su producción poética alrededor de la metáfora del viaje y del espacio simbólico de la ciudad, Adeus Norte (1991). Muestra un gran empeño en llevar la poesía por veredas universalistas, dialogando con otros autores. Culturalismo, visión intimista y, sobre todo, arquitecturas simbólicas decadentes y saudosas conforman el esqueleto de la poesía no cívica de Xosé María Álvarez Cáccamo. La memoria y el autoconocimiento se esconden debajo de la casa y del espejo ${ }^{9}$ que sugieren caminos hacia el cuestionamiento de la existencia. Por su parte, Xulio L. Valcárcel nos descubre una poesía casi pictórica en Memoria de agosto (1993) pero que ha dado muestras de vitalismo y erotismo en muchas ocasiones, especialmente en sus primeiros libros. Sin embargo, el nombre que en estos últimos años se asocia a una curiosa mezcla entre erotismo y decadentismo es el de Miguel Anxo Fernán Vello, autor de Memorial de blancura (1985).

\section{"DÍAS CONTRA FOTOCOPIAS" (ANTÓN R. REIXA)}

En los márgenes de esta poesía dominante, de la que apenas damos el muestrario esencial para una visión de conjunto, caminan otras propuestas, con desigual eco y con desigual recepción que sin embargo es necesario tener en cuenta porque ellas son los antecedentes inmediatos de muchas propuestas que ahora encontramos en los poetas de los noventa (la tiranía de las décadas es caprichosa pero, por ahora, útil). Frente al regusto crepuscular que dejan muchas de las voces que se adscriben a la poesía dominante, reencontramos visiones vitalistas, realidades pintadas con colores diversos y llenas de contrastes. A los ya citados Antón Reixa, Manuel Rivas y Rompente hai que sumar otros nombres, que, proponen un cambio en el tono poético y apuestan por el prosaismo, la narratividade y el acercamiento al lector. Lois Pereiro, convertido ahora en un mito para los más jóvenes propone en sus dos libros, Poemas 1981/1991 (1992) y Poesía última de amor e enfermidade (1995) una poesía

\footnotetext{
9 "O azougue representa simbolicamente o anceio do alquimista de transmutar a materia e o espírito levándoos do transitorio ó estable. Este desexo do alquimista constitúe un proceso análogo ao traballo do poeta, quen pretende converter en inmutábel (obxectivamente utópico) o que, procedendo da experiencia, caracterízase pola súa fundamental provisionaldade" (CÁCCAMO, 1983)
} 
existencialista desgarrada, nada complaciente y apegada a la certeza de la vida y de la muerte desde una óptica underground. Poesía y biografía se van confundiendo muchas veces y juntas escriben un personaje llamado Lois Pereiro que conmueve por lo extremo de las situaciones vitales que allí aparecen. Luisa Castro, que por edad pertenece a la promoción de los 90, publicó en 1988 su jovencísimo Baleas e baleas, donde vomita un texto irreverente en el que hay un yo lírico cambiante, que casi siempre es una adolescente de mirada surrealista, engañosamente naif, perversa que nos pinta un universo desbocado, vitalista y cruel. Todos ellos son precedentes claros de las ficcionalizaciones que triunfan a finales de siglo.

Con el relevo generacional a mediados de los noventa resurgen viejos fantasmas y viejos conflictos, pero ahora en la poesía, como en el pensamiento en general, se rechaza la idea del modelo único y se potencia la heterogeneidad. Reaparece la tensión entre el poeta y la sociedad de la que forma parte. Sin embargo ahora ya no se acude a la dialéctica marxista para verbalizarla; los nuevos tiempos imponen nuevos lenguajes. En la nueva vuelta de la espiral el conflicto revolución-esteticismo (que, obviamente, se podría retratar de otras maneras) se transforma en un choque entre poesía y comunicación frente a poesía y conocimiento, retomando términos que habían sido manejados ya por la generación anterior, una generación que publica sus obras más maduras e interesantes al mismo tiempo que los más jóvenes reivindican un espacio propio. Son de nuevo los certámenes, los espacios críticos, las colecciones especializadas, la creación de canales poéticos (especialmente prolíficos en lo que respecta a editoriales alternativas o la propagación de recitales) los campos de batalla. Por lo tanto, estamos en la segunta vuelta de la espiral desde el año 1975: la disputa entre dos promociones simultáneas, con dos maneras de afrontar las relaciones entre escritura y sociedad. Estas nuevas voces se caracterizan por la desbarroquización, el interés por el presente, la narratividad y una voz poética que parece una matrioska que alberga en su interior muchas voces diferentes. Si la poesía dominante de los ochenta se podría caracterizar por el logocentrismo y la intertextualidad, las propuestas más interesantes de los noventa se centran en la ficcionalización y la interdiscurisvidad.

\section{“A LÚA NO PROBADOR” (FRAN ALONSO)}

Desde comienzos de los noventa vemos cómo empiezan a surgir entre los más jóvenes la necesidad de proponer alternativas que rompan con una buena parte del discurso dominante (esto es, el más esteticista). A partir de aquí empiezan a cuajar distintas tendencias que tienen sus precedentes inmediatos en la promoción anterior. En otro lugar (González, 1997) propuse un abanico de tendencias coexistentes que ahora reviso. A mi modo de ver podemos hablar de cuatro rutas poéticas básicas: la construcción del discurso femenino, la ficcionalización de lo cotidiano, los experimentalismos y la poesía del conocimiento. 
La construcción del discurso femenino se manifiesta de una manera contundente a partir del año 1991 con la publicación de Metáfora da metáfora de María Xosé Queizán (una escritora que pertenece a la última generación de jóvenes escritores de la dictadura, la Nova Narrativa Galega, pero siempre ha estado en la vanguardia del movimiento feminista ${ }^{10}$ ) y Uránia de Chus Pato. Pero ya antes habían aparecido indicios claros de esta eclosión de mujeres que se apoderan de la palabra para acomodar un espacio y una voz propias. Este es un espacio heterogéneo en el que conviven escritores de diferentes edades y estéticas contrapuestas pero que coinciden en la necesidad de deconstruir y reapropiarse del discurso como estrategia ideológica. Fue otra poeta mayor, Xohana Torres, quien con su "Eu tamen navegar" abrió el camino. A partir de aí surgieron otras voces que parecen seguir una estrategia preconcebida. Primeiro se centraron en la reapropiación del imaginario y del discurso, como la ya citada María Xosé Queizán, Ana Romaní en Das últimas mareas (1994), Xela Arias y Chus Pato (la más rupturista y sorprendente, con sus poemas herméticos, caóticos y cargados de compromiso). Después se empezó a reivindicar el malditismo, que se desparrama por la mayoría de los textos, pero que se podría resumir en el poemario de Isolda Santiago, Flor de tan mal xardín (1994). Y, finalmente, la pornografía como actitud deconstructiva más provocadora, con la recuperación del erotismo para la voz femenina, tal como proponen Olga Novo, con Nós nus (1997) y Lupe Gómez con su Pornografía (1995). Por supuesto, la poesía de mujer es un universo de heterogeneidad y es necesario analizar sus propuesta también desde otras perspectivas estéticas. Entre las más jóvenes, como Emma Couceiro con su Humidosas (1997), se constata un deseo de escribir con normalidad desde la conciencia femenina, desplazando a un segundo plano los compromisos genéricos, que quedan ahora en un estado latente.

Más allá de los criterios estéticos, la poesía de mujer, en su conjunto, se presenta como un movimiento poético transgresor y consistente que concibe el tex to como un poderoso ideologema. Y lo cierto es que su visión desde la otredad se va propagando e incluso interfiere en la escritura masculina.

La recuperación de la poesía como un espacio de lo cotidiano, como ya se ha apuntado, era una alternativa que caminaba al margen en los años 80 pero que en los 90 se va imponiendo con fuerza porque se reestablece la comunica-

${ }^{30}$ Ella es la directora de la revista literaria feminista Festa da Palabra Silenciada, que sirvió de plataforma para la formación del movimiento reivindicativo que en los noventa vive la literatura gallega de mujer. Sirvió además como espacio abierto en el que publi." // Así falou Penélope caron por primera vez las poetas de hoy.

"El poema fue publicado primero en un monográfico sobre Xohana Torres en Festa da Palabra Silenciada y después fue recogido en Tempo de ría: "Declara o oráculo: / "QUE á banda de solpor é mar de mortos, / incerta, última luz, non terás medo. // QUE ramos de loureiro erguen rapazas. / QUE cor malva se decide o acio. // QUE acades disas patrias a vindima. / QUE amaine o vento, beberás o viño. // QUE sereas sen voz a vela embaten. / QUE un sumario de xerfa polos cons: / Existe a maxia e pode ser de todos. / ¿A que tanto novelo e tanta historia? // EU TAMÉN NAVEGAR." (TORRFS, 1992: 19). 
ción con el lector, buscando su complicidad, provocándolo o embistiendo contra sus emociones. La ficcionalidad poética rompe barreras: hay narradores, personajes e historias. De ser un bardo o un sacerdote para convertirse en una especie de cronista lírico del presente, cargado de ironía y de vitalidad.

Fran Alonso, que es también narrador, comienza su catálogo de lírico de personas corrientes (tan reales como en una foto o un reportaje televisivo) en Persianas, pedramol y otros nervios (1992) y lo lleva a un realismo insospechado en Tortillas para los obreros (1996). Indaga en el terreno de las emociones y nos destapa sentimientos, contradicciones y angustias con un gran respeto por los personajes y al mismo tiempo una crudeza estremecedora. Anxo Quintela, que había publicado su primer poemario, A sombra dos pavillóns, en 1982, investiga las posibilidades formales de la poesía narrativa en $O$ asasino estrábico (1996), un libro en el que aúna la tensión del decasílabo de verso blanco y la intriga de la novela negra. Por su parte, Antón R. López juega con la ambiegüedad sexual para ofrecernos textos cargados de sorpresa y sensualidad (posiblemente el es el mejor poeta de lo erótico de esta década) e impregnados de ironía en Manual de masoquistas (1990) y Sucios e desexados (1988), aunque en su último libro, $O m$ (1996) se decanta por el misticismo oriental. A veces el presente es un mundo soñado, simbólico e imposible que se nos presentan bajo los ropajes de un neorrealismo mágico, como el universo zoológico de Estevo Creus, autor de Poemas da cidade oculta (1996) y Areados (1997), el mundo que presenta Emma Couceiro o el rural naif de Celso Fernández Sanmartín. Entonces estamos ante una poesía que se ve, se huele, se toca y tiene sabor, porque el mundo sensorial se convierte en un revelador mágico de lo oculto.

Cuando el presente se concibe como un espacio de encuentro temporal dinámico y culturalista se convierte en deudor del magisterio poético de Méndez Ferrín. No se trata del venecianismo de postal, ni del decadentismo saudoso porque los textos están compuestos desde la ironía, la denuncia y el collage de elementos del día a día. Chus Pato, que por edad pertenece a la promoción anterior pero por práctica poética hay que encuadrar en los noventa, es la voz más poderosa del momento. Desde Urania (1991) hasta A ponte das poldras (1996) construye el presente tal como lo ve, es decir, como un hervidero, como un lugar de encuentro simultáneo de la historia, de las presencias y de los silencios, de las culturas, de todo lo que entra en contacto en una sincronía dada como si todavía no hubiese pasado por el molde que establece unha lectura ordenada y convencional. En esta misma línea interdiscursiva se encuentra Xavier Cordal, que en Arianrod (1993) había presentado su aportación al celtismo y el arturismo (temas recurrentes y característicos de nuestro discurso literario), y en sus últimos libros, como su Afásia (1997), ha optado por acomodar culturalismo y visión crítica de la realidad en una propuesta dominada por la sensación de fragmentariedad.

Los experimentalismos son pequeñas, pero interesantes islas de poetas inclasificables. En nuestro sistema literario ha habido siempre un triunfo de las formas convencionales o controladamente inclasificables. El referente más 
claro y (re)conocido es el de Rompente, por eso no es nada raro que la aportación más interesante de los últimos años es el Bonus Track (1997) de Manuel Romón ${ }^{12}$, aunque muchos la tachan de deshumanizadora, mecanicista y fría. Entre los más jóvenes encontramos el ya desaparecido Colectivo Ronseltz, Manuel Cortés, Xavier Santiago y Manuel Outeiriño.

La poesía del conocimiento apuesta por la temática transcendente, por el erotismo y por la depuración de la forma ${ }^{13}$. Se hacen incursiones en la métrica clásica. Miro Villar es el ejemplo más destacado y que nos ofrece sus mejores textos en Abecedario da desolación (1997). Pero, sobre todo, se construyen poemas intimistas en los que se cita a los clásicos con un lenguaje más desnudo y sincero, tal como hace Rafa Villar en su poemas marinos de $A$ sotavento dunha singradura (1995), e incluso conservando el aire decadente, como ocurre con Das últimas ruinas (1994) de Martín Veiga. En esta línea de intimismo y cognición encontramos a algunas de las más jóvenes poetas, como Helena de Carlos, con su Alta casa (1996), que se presenta como una de las voces más interesantes de esta tendencia. Es necesario citar también a Anxos Romero o la más preciosista y vigorosa Yolanda Castaño, autora de Elevar as pálpebras (1995). En este ámbito hay que destacar la voz de Arturo Casas, un poeta que por edad está en la frontera generacional, autor de Pedro de Nadir (1995). La suya es la incursión más depurada y de mejores resultados de la poética del conocimientoi y en sus textos propone una hermenéutica creativa del universo.

\section{"AGORA QUE TODOS OS POETAS DO MUNDO LLE CAERÁN ENRIBA" (CHUS PATO)}

El viaje poético desde 1975 se puede organizar, por lo tanto, en tres etapas. En los años de la transición política el espíritu Rompente, con su recuperación de la vanguardia y sus deseos de transformación de la sociedad, significaron una puesta al día del lenguaje poético gallego que no había experimentado hasta el momento (excepto algunas tentativas surgidas en Brais Pinto), acercando los versos y el galleguismo al nuevo estilo de vida de la gente, que cada vez más vivía en el medio urbano y participaba de la aldea global. Los años 80 significan el deseo de una normalidad literaria y de la necesidad de construir un discurso exportable y equiparable a las propuestas que dominaban en las literaturas de nuestro alrededor. Los poetas se convierten en los constructores por excelencia de un registro culto, por eso apuestan por un clasicismo decadente que rehuye el coloquialismo y permite reescribir los tópicos universales. En este mismo período publican otros autores que Sousa.

'? Cuenta con la colaboración de Julián Hernández (miembro de Siniestro Total) y Alberto de

$1:$ Ésta es la tendencia que Luciano Rodrigi noventa, en una propuesta continuista que rehuye la heterogeneidad que aquí presentamos. 
ofrecen vías alternativas: rehuyen del esteticismo para retomar la comunicación con la gente y ofrecen mundos imaginarios próximos. Los noventa se presentan como un revoltillo heterogéneo de tendencias en el que se aprecia un regreso al deseo de volver a entrar en contacto con el lector, con la tranformación de la sociedad, e incluso ayudar a despertar conciencias. La poesía de mujer, la ficcionalización de lo cotidiano y la poesía de la comunicación se presentan entonces como las rutas más sólidas, y en los márgenes caminan las calas experimentales.

La poesía siempre ha tenido en Galicia un peso importante, concebida a menudo como un espacio simbólico importante para la experimentación, la resistencia, la articulación de la identidad y la modernidad. Estéticas e ideologías entran en combate en este espacio para proponer modelos de escritura y de sociedad. En un sistema literario como el gallego, mejor dicho, en una cultura como la gallega el poeta pocas veces puede ser ajeno al compromiso con su entorno: "la lengua que yo he aprendido arrastra la garganta / balbucea revueltas / ni forma ni contenido. apenas los nexos" (Xabier Cordal).

\section{BIBLIOGRAFÍA CITADA}

Álvarez CácCamo, Xosé María. “A poesía e os espellos”. Escrita (1983): 17.

BALTRUSCH, Burghard."Estéticas en combate. Apuntamentos acerca dun cambio cultural e búsquedas de identidade na literatura galega contemporánea". Anuario de Estudios Literarios Galegos (1994) (1995): 84-96.

- "Filosofía e estética da retranca maila súa intencionalidade e reflexividade en Suso de Toro e Antón Reixa". Actas do 5o Congreso Internacional de Estudios Galegos. Trier 8-11 de outubro de 1997 (en imprenta).

Cochón, Iris. Unha lectura de Con Pólvora e Magnolias de X.L. Méndez Ferrín. Documento $1^{\circ}$ Encontro de Escritores de Galiza, Euskalerria e Països Catalans. 22-23-24 Xuño 1984. Barcelon-Sitges-Poblet. Hoja incluida en Escrita 5 (1984).

FONTE, Ramiro. "Una poesía europea". Monográfico Poesía gallega contemporánea de Litoral, 209-210 (1996): 29-35.

García-Posada, Miguel (ed.). Poesía española. La nueva poesía (1975-1992). Barcelona: Crítica, 1996.

GONZÁLEZ FERNÁNDEZ, Helena. "A poesía dos noventa e a reacción contra a poesía dominante". Chineses, supl. de O Correo Galego (3-1-1997): 3-8.

GONZÁLEZ-MILLÁN, Xoán. "Do nacionalismo literario a unha literatura nacional. Hipóteses de traballo para un estudio institucional da literatura galega". Anuario de Estudios Literarios Galegos (1994)(1995): 67-81.

- Literatura e sociedade en Galicia (1975-1990). Vigo: Xerais, 1994.

Monteagudo, Henrique. "Dez anos de poesía galega 1975-1985". Grial, 89 (1985): 268-293. 
ReiXA, Antón R. "Con Edoardo Sanguinetti en Compostela". Escrita 4 (1984): 4.

Rodríguez, Luciano (ed.). Desde a palabra, doce voces. Nova poesía galega. Barcelona: Sotelo Blanco, 1985.

- Seis poetas gallegos de hoy. Granada: Diputación, 1995.

TORRES, Xohana. Tempo de ría. A Coruña: Espiral Maior, 1992.

VILAVEDRA, Dolores. "La narrativa gallega de los 80 . Una década de búsqueda". Revista de Lenguas y Literaturas Catalana, Gallega y Vasca (1994 y 1995), IV (1996): 231-236. 